\title{
Kant, Hegel, and the Fate of Non-Conceptual Content ${ }^{1}$
}

\author{
Robert Hanna
}

\begin{abstract}
In this paper, I argue that if you want to be a consistent Kantian transcendental idealist, then you have to defend the strongest possible version of Non-Conceptualism; but if you want to be a consistent Conceptualist, then Hegel was absolutely right that you have to go all the way to absolute idealism and what I call 'super-Conceptualism', because the strongest possible version of Non-Conceptualism trumps any weaker version of Conceptualism. So you cannot consistently split the difference between Conceptualism and super-Conceptualism in the way that, e.g., contemporary neo-Hegelians like John McDowell and Robert Brandom attempt to do.
\end{abstract}

[S]ince an object can appear to us only by means of ... pure forms of sensibility, i.e., be an object of empirical intuition, space and time are thus pure intuitions that contain a priori the conditions of the possibility of appearances, and the synthesis in them has objective validity. The categories of the understanding, on the contrary, do not represent to us the conditions under which objects are given in intuition at all, hence objects can indeed appear to us without necessarily having to be related to functions of the understanding, and therefore without the understanding containing their a priori conditions. Thus a difficulty is revealed here that we did not encounter in the field of sensibility, namely how subjective conditions of thinking should have objective validity, i.e., yield conditions of the possibility of objects; for appearances can certainly be given in intuition without functions of the understanding. ... [T] hat objects of sensible intuition must accord with the formal conditions of sensibility that lie in the mind a priori is clear from the fact that otherwise they would not be objects for us; but that they must also accord with the conditions that the understanding requires for the synthetic unity of thinking is a conclusion that is not 
so easily seen. For appearances could after all be so constituted that the understanding would not find them in accord with the conditions of its unity, and everything would then lie in such confusion that, e.g., in the succession of appearances nothing would offer itself that would furnish a rule of synthesis and thus correspond to the concept of cause and effect, so that this concept would be entirely empty, nugatory, and without significance. Appearances would nonetheless offer objects to our intuition, for intuition by no means requires the functions of thinking (CPR A8991/B122-123, underlining added).

Thus pure science presupposes liberation from the opposition of consciousness. It contains thought in so far as this is just as much the object in its own self, or the object in its own self is so far as it is equally pure thought. As science, truth is pure self-consciousness in its self development, and has the shape of the self, so that absolute truth of being is the known Notion and the Notion as such is the absolute truth of being. This objective thinking, then, is the content of pure science. Consequently, far from being formal, far from standing in need of a matter to constitute an actual and true cognition, it is its content alone which has absolute truth, or, if one still wanted to to employ the word matter, it is the veritable matter-but a matter which is not external to the form, since this matter is rather pure thought and hence the absolute form itself. Accordingly, logic is to be understood as the system of pure reason, as the realm of pure thought. This realm is truth as it is without veil and in its own absolute nature. It can therefore be said that this content is the exposition of God as he is in his eternal essence before the creation of nature and a finite mind (SL 49-50, underlining added).

\section{Introduction}

For better or worse, the contemporary debate about Conceptualism vs. NonConceptualism, a.k.a. 'the debate about non-conceptual content', ${ }^{2}$ or NCC, is ineluctably intertwined with the history of German idealism, and more specifically with the development of German idealism from Kant's transcendental idealism (TI) to Hegel's absolute idealism (AI). The debate about NCC is also ineluctably intertwined with the foundations of Analytic philosophy, ${ }^{3}$ but I will mostly bracket that important connection here, except for a few short remarks later in this Introduction and at the end of the paper. 


\section{Robert Hanna}

So, more precisely, how is the debate about NCC ineluctably intertwined with the development of German idealism from Kant's TI to Hegel's AI? The two-part soundbite version of the answer I want to give to that question is,

first, that the existence of NCC is a necessary condition of the truth of Kant's TI, but also a sufficient condition of the unsoundness of both the $\mathrm{A}$ and $\mathrm{B}$ edition versions of the Transcendental Deduction of the Categories in the Critique of Pure Reason, and that Kant unsuccessfully struggled with this dilemma throughout the development of the Critical philosophy,

and

second, that Hegel brilliantly recognized this problem, and took the necessary philosophical steps that Kant himself could never take, which are

(i) to absorb NCC fully into conceptual content,

(ii) to identify the world itself with a systematic totality of concepts, understood as essences (AI), and

(iii) to identify a priori knowledge with a holistic immediate grasp of an overarching systematic conceptual worldessence, a.k.a. the Concept (Begriff ), a.k.a. the concrete universal, thereby turning Kant's deeply conflicted Conceptualism into Hegel's super-Conceptualism.

And the soundbite version of the philosophical moral of the story is this:

If you want to be a consistent Kantian transcendental idealist, then you have to defend the strongest possible version of Non-Conceptualism; but if you want to be a consistent Conceptualist, then Hegel was absolutely right that you have to go all the way to AI and super-Conceptualism, because the strongest possible version of Non-Conceptualism trumps any weaker version of Conceptualism. So you cannot consistently split the difference between Conceptualism and super-Conceptualism in the way that, e.g., contemporary neo-Hegelians like John McDowell $^{4}$ and Robert Brandom ${ }^{5}$ attempt to do.

But in order to state all these claims more carefully and clearly, I will need to define some notions and terms. ${ }^{6}$

By 'cognition' or Erkenntnis I mean the conscious mental representation of objects, which is essentially the same as what Phenomenologists and other philosophers of mind call intentionality. ${ }^{7}$ Cognition, i.e., conscious mental representation of 


\section{Kant, Hegel, and the Fate of Non-Conceptual Content}

objects, a.k.a. intentionality, occurs via mental acts, states, or processes that possess cognitive, mental-representational, or intentional 'content' or Inhalt, which is

(i) propositional, descriptive, depictive, and/or referential information or Kenntnis about objects,

(ii) what individuates cognitive acts, states, or processes, and

(iii) what normatively guides cognitive acts, states, or processes, e.g., by providing truth-conditions, or correct description conditions, or fitting depiction conditions, or referential accuracy conditions for them.

In these ways, a theory of cognitive, mental-representational, or intentional content is a cognitive semantics. ${ }^{8}$

It is also crucial to distinguish between

(i) cognitive content, as per the above characterization, and

(ii) phenomenal content, which is the conscious or subjective experiential specific characters (including sensory characters, desiderative characters, and affective characters) of cognitive acts, states, or processes, that are contingently or necessarily associated with the cognitive contents of those mental acts, states, or processes.

Whereas a theory of cognitive content is a cognitive semantics, a theory of phenomenal content is a cognitive phenomenology. This distinction is important, because both Conceptualism and Non-Conceptualism are cognitive-semantic theories, i.e., theories of cognitive content. Nevertheless, the most persistent myth about NonConceptualism is that it is at best a cognitive phenomenology and at worst just a causal theory of unstructured sensations inherently lacking cognitive content. ${ }^{10}$ Interestingly enough, as far as I can tell, this philosophical myth originally stems from Hegel's misinterpretation of Kant as a subjective idealist, ${ }^{11}$ taken together with the 'Sense Certainty' section of Phenomenology of Spirit, mistakenly understood as a knock-down critique of Kant's theory of empirical intuition, which was then uncritically transmitted via Oxford neo-Kantianism, C.I. Lewis's Mind and the World Order, and Pittsburgh neo-Hegelianism, in the canonical form of Wilfrid Sellars's attack on 'the myth of the given'. So, in effect, it is 'the myth of the myth of the given'. 12

In any case, the doctrine of Conceptualism says that all cognitive content is fully determined by our conceptual capacities and that no non-rational or nonhuman animals are capable of cognition, i.e., conscious mental representation of objects, a.k.a. intentionality. By sharp contrast, the doctrine of Non-Conceptualism says that not all cognitive content is fully determined by our conceptual capacities, that some cognitive content is fully determined by our non-conceptual 


\section{Robert Hanna}

capacities, and that all minded human or non-human animals are capable of cognition, i.e., conscious mental representation of objects, a.k.a. intentionality.

In turn, there are two kinds of Non-Conceptualism:

(i) content Non-Conceptualism, which says that non-conceptual content and conceptual content are two different kinds of cognitive content, and

(ii) state or possession-theoretic Non-Conceptualism, which says that even though all cognitive content is in fact conceptual, it is also possible to be in a mental act, state, or process that relates to this content in such a way as not to possess that content, and such acts, states, or processes are 'non-conceptual' by virtue of their failing the conceptpossession conditions of those acts, states, or processes.

A crucial thing to note about state or possession-theoretic Non-Conceptualism is that it is in fact 'non-conceptualist' only in a Pickwickian sense, since it still holds that all cognitive content is essentially conceptual. Correspondingly, a crucial thing to note about content Non-Conceptualism is that it sub-divides into two kinds, according to whether it holds that non-conceptual content is

(i) essentially different from conceptual content, which is essentialist content Non-Conceptualism,

or

(ii) only accidentally or contingently different from conceptual content, which is non-essentialist content Non-Conceptualism.

Now Kant's TI says that the intrinsic forms or structures of the manifestly real world necessarily conform to the a priori forms or structures of the innately specified cognitive capacities or powers of rational human animals, whose basic or proper objects are always spatiotemporal sensory appearances or phenomena, and never non-spatiotemporal, non-sensory, mind-independent things-inthemselves or noumena, and also that the converse classical rationalist or empiricist thesis-i.e., that the rational human mind conforms to its cognitive objects - is not the case. In other words, the core of Kant's TI is The Conformity Thesis. The Conformity Thesis is also variously known as 'Kant's Copernican hypothesis', 'Kant's Copernican revolution', and 'Kant's Copernican turn'. The Conformity Thesis presupposes Kant's fundamental thesis that the cognitive capacities or powers of rational human animals are inherently dual, or two-sided, including

(1) our finite embodied animal capacity for sensibility (Sinnlicbkeit), which is receptively responsive to given actual individuals and their individuality in space and time, via intuitions (Anschaunngen), whether these are delivered to us by sense perception of the external world 
(outer sense) or by our own subjectively experiential or phenomenally conscious lives (inner sense), and is not always self-consciously (apperceptively) accessible to us, and

(2) our discursive intellectual and rational capacity for understanding (Verstand) which is spontaneously responsive to reasons, judgments, and logic, via concepts (Begriffe), and is always, at least in principle, selfconsciously (apperceptively) accessible to us.

Just to give this fundamental thesis a name, let us call it Kant's cognitive dualaspectism.

By sharp contrast to Kant's TI, Hegel's AI says that the world in itself, or in its supersensible nature, is literally constituted by or made out of the concepts that occur essentially in the logically dialectical, inherently developmental and dynamic, and synoptically holistic thinking of a single rational, self-conscious subject, a.k.a. Spirit (Geist). ${ }^{13}$ This means that according to Hegel's AI, the logically dialectical, inherently developmental and dynamic, and synoptically holistic singular rational self-conscious thinking that immediately grasps the systematic conceptual world-essence, a.k.a. the Concept, a.k.a. the concrete universal — a very special kind of thinking that Kant, and Hegel following him, call 'intuitive understanding'-and the world in itself are identical, in the sense that the latter ('being') is nothing over and above the former ('thought'). In other words, AI is a radically monistic idealistic thesis_ as it were, Kant taken through the looking-glass of Spinoza, bathed in the glow of the mutually competing magic lanterns of Fichte and Schelling - and Hegel's Conceptualism is a super-Conceptualism. ${ }^{14}$

Granting me all those preliminaries as backdrop, then in the rest of this paper I want to argue for five claims.

First, the very idea of essentially non-conceptual content, or ENCC, is a necessary condition of Kant's TI, and yet at the same time the existence of ENCC is sufficient to provide a fundamental problem for Kant's TI: The Transcendental Deduction of the Categories has a logical gap in it by virtue of the existence of ENCC, and is therefore unsound. ${ }^{15}$ This is Kant's deeply conflicted Conceptualism, and he struggles with this dilemma throughout the Critical philosophy.

Second, as Hegel brilliantly recognized, the only way of adequately solving the problem of The Gap in the Deduction is to reject the very idea of ENCC, and to sublate the notion of NCC, whether understood in a state Non-Conceptualist way, or as the mere mythical causal-sensory "given," in the notion of conceptual content, and then move forward from Kantian TI to AI+ super-Conceptualism. Therefore the fate of NCC and the fate of Kantian TI are one and the same. 


\section{Robert Hanna}

Third, on the one hand, given Hegel's brilliant recognition, the only way consistently to defend the existence of ENCC and Kantian TI is to affirm The Gap in the Deduction and proceed accordingly. This is the strongest possible version of Kantian Non-Conceptualism.

Fourth, but on the other hand, again given Hegel's brilliant recognition, the only way consistently to defend Conceptualism against the strongest possible version of Kantian Non-Conceptualism, i.e., Kantian essentialist content NonConceptualism + TI + affirming The Gap, is to adopt Hegelian AI + superConceptualism.

Fifth, and finally, the philosophical moral of this story is that if you are going to be a contemporary idealist, then the basic options are either

(i) Kantian essentialist content Non-Conceptualism+TI+affirming The Gap

or

(ii) Hegelian $\mathrm{AI}+$ super-Conceptualism.

You cannot consistently have it both ways, and therefore you will need to make your choice.

For example, contemporary neo-Hegelian attempts to defend Conceptualism, such as those developed by McDowell and Brandom, without going all the way to classical Hegelian AI and super-Conceptualism, are doomed, because Kantian essentialist content Non-Conceptualism + TI + affirming The Gap trumps any weaker version of Conceptualism.

\section{Kant's Master Argument for Transcendental Idealism}

Kant's famous letter to Marcus Herz in 1772 (PC 10: 129-135 [21 Feb. 1772]) states the basic rationale for TI as clearly and distinctly as possible. Then in the Critique of Pure Reason, Kant explicitly formulates and justifies TI in terms of that basic rationale. Here are the relevant parts of the letter to Herz, followed by the relevant corresponding texts from the first Critique.

As I thought through the theoretical part [of The Limits of Sense and Reason], considering its whole scope and the reciprocal relations of its parts, I noticed that I still lacked something essential, something that in my long metaphysical studies I, as well as others, had failed to pay attention to and that, in fact, constitutes the key to the whole secret of hitherto still obscure metaphysics. I asked myself: What is the ground of the relation of that in us which we call "representation" to the object? 
If a representation is only a way in which the subject is affected by the object, then it is easy to see how the representation is in conformity with this object, namely as an effect in accord with its cause, and it is easy to see this modification of our mind can represent something, that is, have an object. Thus the passive or sensuous representations have an understandable relationship to objects, and the principles that are derived from the nature of our soul have an understandable validity for all things insofar as those things are supposed to be objects of the senses. In the same way, if that in us which we call "representation" were active with regard to the object, that is, if the object were created by the representation (as when divine cognitions are conceived as the archetypes of all things), the conformity of these representations to their objects could be understood. Thus the possibility of both an intellectus archetypi (on whose intuitions the things themselves would be grounded) and an intellectus ectypi (which would derive the data for its logical procedure from the sensible intuition of things) is at least intelligible. However, our understanding, through its representations, is not the cause of the object.... nor is the object the cause of the intellectual representations in the mind.... Therefore the pure concepts of the understanding must not be abstracted from sense perceptions, nor must they express the reception of representations through the senses; but though they must have their origin in the nature of the soul, they are neither caused by the object nor bring the object into being. In my dissertation I was content to explain the nature of intellectual representations in a merely negative way, namely, to state that they were not modifications of the soul brought about by the object.

However I silently passed over the further question of how a representation that refers to the object without being in any way affected by it can be possible. I had said: The sensuous representations present things as they appear, the intellectual representations present them as they are. But by what means are these things given to us, if not by the way in which they affect us? And if such intellectual representations depend on our inner activity, whence comes the agreement that that they are supposed to have with objects-objects that are nevertheless not possibly produced thereby? And the axioms of pure reason concerning these objects-how do they agree with 


\section{Robert Hanna}

these objects, since the agreement has not been reached with the aid of experience? In mathematics this is possible, because the objects before us are quantities and can be represented as quantities only because it is possible for us to produce their mathematical representations (by taking numerical units a given number of times). But in the case of relationships involving qualities - as to how my understanding may form for itself concepts of things completely a priori, with which concepts the things must necessarily agree, and as to how my understanding may formulate real principles concerning the possibility of such concepts, with which principles experience must be in exact agreement, and which nevertheless are independent of experience-this question, of how the faculty of understanding achieves this conformity with the things themselves, is still left in a state of obscurity.

Plato assumed a previous intuition of divinity as the primary source of the pure concepts of the understanding and of first principles. [Malebranche] believed in a still-continuing perennial intuition of this primary being. Various moralists have accepted precisely this view with respect to basic moral laws. Crusius believed in certain implanted rules for the purpose of forming judgments and ready-made concepts that God implanted in the human soul just as they had to be in order to harmonize with things. Of these systems, one may call the former the influxum byperphysicum and the latter the harmonium preastabilitatem intellectualem. But the deus ex machina is the greatest absurdity one could hit on in the determination of the origin and validity of our knowledge. It has-beside its deceptive circle in the conclusion concerning our cognitionsalso this additional disadvantage: it encourages all sorts of wild notions and every pious and speculative brainstorm (PC 10: 129-135).

Up to now it has been assumed that all our cognition must conform to the objects; but all attempts to find out something about them a priori through concepts that would extend our cognition have, on this presupposition, come to nothing. Hence let us once try whether we do not get farther with the problems of metaphysics by assuming that the object must conform to our cognition, which would agree better with the requested possibility of an a priori cognition of them, which is to establish something 
about objects before they are given to us.... If intuition has to conform to the constitution of the objects, then I do not see how we can know anything of them a priori; but if the object (as an object of the senses) conforms to the constitution of our faculty of intuition (Anschauungsvermögens), then I can very well represent the possibility to myself (CPR Bxvi-xvii).

Now there are only two ways in which a necessary agreement of experience with the concepts of its objects can be thought: either the experience makes these concepts possible, or these concepts make the experience possible. The first is not the case with the categories (nor with pure sensible intuition); for they are a priori concepts, hence independent of experience (the assertion of an empirical origin would be a sort of generatio aequivoca). Consequently only the second way remains (as it were a system of the epigenesis of pure reason): namely, that the categories contain the grounds of the possibility of all experience in general from the side of the understanding.... If someone still wanted to propose a middle way between the only two, already named ways, namely, that the categories were neither self-thought a priori first principles of our cognition, nor drawn from experience, but were rather subjective predispositions of our thinking, implanted in us along with our existence by our author in such a ways that their use would agree exactly with the laws of nature along which experience runs (a kind of preformation-system of pure reason), then (besides the fact that on such a hypothesis no end can be seen to how far one might drive the presupposition of predetermined predispositions for future judgments) this would be decisive against the supposed middle way: that in such a case the categories would lack the necessity that is essential to their concept. For, e.g., the concept of cause, which asserts the necessity of a consequent under a presupposed condition, would be false if it rested only on a subjective necessity, arbitrarily implanted in us, of combining certain empirical representations according to a rule of relation. I would not be able to say that the effect is combined with the cause in the object (i.e., necessarily), but only that I am so constituted that I cannot think of this representation otherwise than as so connected; which is precisely what the skeptic wishes most, for then all our insight through the supposed objective validity of 


\section{Robert Hanna}

our judgments is nothing but sheer illusion, and there would be no shortage of people who would not concede this subjective necessity (which must be felt) on their own; at least one would not be able to quarrel with anyone about that which merely depends on the way in which his subject is organized (CPR B166-168).

And here is my reconstruction of Kant's master argument for TI, as follows.

We assume that rational human animals possess some veridical a priori conscious representations of objects, including both individuals and also the facts that are the truth-makers of true a priori judgments. How are these veridical a priori conscious representations of objects possible? On the assumption that we do indeed possess some veridical a priori conscious representations of objects, then we have to be able to rule out the skeptical possibility that the relation between these a priori representations and their objects is merely a massive coincidence: since if that were so, then that relation is at best accidental and at worst could have just as easily been illusory in a nearby possible world, and then fully reliable, veridical a priori cognition is impossible. Call this The Problem of Cognitive-Semantic Luck. But on the assumption that the rational human mind passively conforms to its objects, then The Problem of Cognitive-Semantic Luck cannot be solved. For under that assumption, consider, in their $17^{\text {th }}$ and $18^{\text {th }}$ century versions, on the one hand,

(i) Platonism,

(ii) Cartesian 'clear and distinct ideas' together with the Cartesian thesis that God-exists-and-is-not-a-deceiver, and

(iii) Leibnizian pre-established harmony.

Then the connection between a priori cognition and its objects is either nothing but a metaphysical mystery (Platonism), or else a question-begging deus ex machina (Cartesianism, Leibnizianism). Now under the same assumption, consider, on the other hand, $17^{\text {th }}$ and $18^{\text {th }}$ Empiricism and the thesis that the connection between a priori cognition and its objects is causal. Then the connection is such that it explains only the aposteriority of veridical objective cognition, not its apriority. Therefore the only remaining alternative is to reject the initial assumption of the passive conformity of rational human mind to its objects, and hypothesize contrariwise that objects necessarily conform to the innately specified cognitive capacities or powers of our minds, and that rational human minds are inherently active or spontaneous with respect to cognizing the essential forms of those objects, i.e., Kant's TI. In the Prolegomena to Any Future Metaphysics in 1783 and in the B or 1787 edition of the first Critique, Kant re-focused and refined this master argument by narrowing down 'How are veridical a priori conscious representations of objects possible?' 
to 'How are synthetic a priori judgments possible?', but the basic rationale for TI remains the same.

\section{Kant's Essentialist Non-Conceptualism vs. Kant's Deeply Conflicted Conceptualism}

An essential feature of Kant's TI, however, in view of his cognitive dual-aspectism, is that TI comes in two logically distinct phases:

(1) TI for sensibility/intuitions

and

(2) TI for understanding/concepts.

The two phases were also historically distinct. The basic argument for TI with respect to sensibility/intuitions was already in place by the time of the Inangural Dissertation in 1770, and it is carried over almost without revision into the Transcendental Aesthetic. But it took Kant until 1781 to work out the basic argument for TI with respect to understanding/concepts, i.e., to work out the Transcendental Deduction of the Pure Concepts of the Understanding; and then it took him another six years, until 1787, to revise and update the Transcendental Deduction.

And here is the main reason that it took Kant $11+6=17$ years to work out, revise, and update the basic argument for TI with respect to understanding/ concepts. The Transcendental Aesthetic establishes the cognitive independence of both empirical and pure intuition from both empirical and pure concepts, and from conceptualization more generally. Hence the original cognitivesemantic argument that Kant supplies in The Transcendental Aesthetic for the a priori necessity and objective validity (empirical meaningfulness) of pure intuition, i.e., the unified formal representations of space and time, cannot be soundly used in and of itself to show the a priori necessity and objective validity of the pure concepts of the understanding, i.e., the Categories. Therefore another, logically distinct argument-strategy must be found in order to demonstrate the a priori necessity and objective validity of the Categories, and, correspondingly, there is a prima facie difficulty for Kant about how to demonstrate this. This point about the cognitive independence of both empirical and pure intuition from both empirical and pure concepts is also captured in the well-known "progression" (Stufenleiter) of representations text at CPR A320/B376-377, which isolates intuitions as a distinct type of cognition in direct contrast to concepts, and is stated explicitly at least three times in the first epigraph above, and more generally, implied throughout the First Section (\$13) of the Transcendental Deduction, 'On the principles of a 


\section{Robert Hanna}

transcendental deduction in general'. And if that were not enough textual evidence, here is more.

That representation which can be given prior to all thinking is called intuition (CPR B132).

The manifold for intuition must already be given prior to the synthesis of the understanding and independently from it (CPR B145, underlining added).

Concept differs from intuition by virtue of the fact that all intuition is singular. He who sees his first tree does not know what it is that he sees (VL 24: 905, underlining added).

So I think that it is clear and undeniable that Kant is a defender of essentialist content Non-Conceptualism, ${ }^{16}$ and as a consequence, that there is a prima facie difficulty for him about how to demonstrate the a priori necessity and objective validity of the Categories.

But there is an apparently serious complication in this philosophical narrative. Kant is clearly and undeniably also a Conceptualist, and indeed the philosophical discoverer or inventor of Conceptualism:

Intuition and concepts .... constitute the elements of all our cognition, so that neither concepts without intuition corresponding to them in some way nor intuition without concepts can yield a cognition.

Thoughts without content (Inhalt) are empty (leer), intuitions without concepts are blind (blind). It is, therefore, just as necessary to make the mind's concepts sensible - that is, to add an object to them in intuition - as to make our intuitions understandablethat is, to bring them under concepts. These two powers, or capacities, cannot exchange their functions. The understanding can intuit nothing, the senses can think nothing. Only from their unification can cognition arise (CPR A50-51/B74-6).

These texts express what I call The Togetherness Principle: Intuitions and concepts are cognitively complementary and semantically interdependent. How can this be reconciled with Kant's essentialist content Non-Conceptualism?

Actually, it is easy enough to see how: Intuitions and concepts are cognitively complementary and semantically interdependent for the purposes of objectively valid empirical judgments only, but outside that context, both objectively valid 'blind intuitions' and also non-objectively-valid 'empty concepts' are possible. 
Here we need to remember Kant's initial definition of the notion of an appearance or Erscheinung: 'the undetermined object of an empirical intuition is called appearance' (CPR A20/B34). Now 'determination' for Kant is conceptual specification, hence an 'undetermined object' is a conceptually unspecified or unconceptualized object. In this way, even though intuitions without concepts are 'blind' and do not include conceptual specification, they are still fully objectively valid cognitions under the objectively valid spatiotemporal forms of intuition, as Kant points out explicitly at CPR A89/B122:

[S]ince an object can appear to us only by means of ... pure forms of sensibility, i.e., be an object of empirical intuition, space and time are thus pure intuitions that contain a priori the conditions of the possibility of appearances, and the synthesis in them has objective validity.

Nevertheless, thoughts without intuitional content are empty and without any empirical meaning or objective validity. In other words, even though it may easily seem otherwise on a superficial reading, The Togetherness Principle both states the cognitive complementarity and semantic interdependence of intuitions and concepts and also is cognitive-semantically asymmetric: 'blind' intuitions still have objective validity, whereas 'empty' concepts do not have objective validity.

Again, what all of this entails is that

(i) although the a priori necessity and objective validity of the forms of intuition can be proved directly by means of the inconceivability of empirical intuitions without the pure formal representations of space and time immanently contained within them and presupposed by them, the same argument for a priori necessity and objective validity will not work for pure concepts, therefore

(ii) there must be a logically distinct argument for the a priori necessity and objective validity of pure concepts that effectively rules out the possibility of what I will call rogue objects, i.e., unconceptualized objects, i.e., empirically intuited objects that do not fall under the Categories.

This logically distinct argument, again, is The Transcendental Deduction of the Categories, which purports to show that all and only the objects of human sensory intuition necessarily fall under and presuppose the a priori pure concepts of the understanding, a.k.a. the Categories. This is manifestly clear, e.g., in the titles of $\$ 20$ and $\$ 24$ in the B Deduction: 'All sensible intuitions stand under the 


\section{Robert Hanna}

categories, as conditions under which alone their manifold can come together in one consciousness' (CPR B143) and 'On the application of the categories to objects of the senses in general' (CPR B150).

\section{The Gap in the A Deduction: Rogue Objects}

Given Kant's TI, the difference between

(i) undetermined or unconceptualized objects of empirical intuition, i.e., appearances, and

(ii) determined or conceptualized-and-empirically-judged empirical objects, i.e., determined or conceptualized-and-empirically-judged appearances,

is of crucial importance for natural science and natural scientific knowledge. This is because only type-(ii) objects are inherently available to natural science, and only the latter will count as material objects in the Newtonian sense. Kant's term-ofart for such objects is objects of experience (CPR A93/B126). Correspondingly, whether in its 'subjective' or 'objective' version, what the A Deduction actually shows is that necessarily, for all objects of rational human cognition, if any object of empirical intuition is also to be a determined/conceptualized material object in the Newtonian natural scientific sense-if any object of empirical intuition is also to be an object of experience-then the Categories are a priori required for the empirical determination/conceptualization of those very objects, i.e., the objects of experience, by means of the a priori synthesis of transcendental imagination, under the original synthetic unity of apperception, via the sub-syntheses of apprehension, reproduction, and recognition (CPR A95-130).

But, unfortunately for Kant, in light of the meaning of the necessary conditional that captures the actual conclusion of the A Deduction, the A Deduction does not thereby show that all objects of empirical intuition must be synthetically determined/conceptualized, and therefore does not thereby show that all objects of empirical intuition must fall under the Categories and be objects of experience. For there could still be some objects of empirical intuition, or appearances, that as yet are not so determined/conceptualized or even cannot be so determined/conceptualized, and thereby fall outside the ontological and epistemic scope of Newtonian natural science.

For clarity's sake, I will call those objects of empirical intuition, or appearances, that are as yet not determined/conceptualized but still can in principle be determined/conceptualized, accidentally rogue objects, and I will call those objects of empirical intuition, or appearances, if any exist, that are as yet not 
determined/conceptualized but also cannot even in principle be determined/ conceptualized, essentially rogue objects. Unless it can be shown by Kant

(i) that all the accidentally rogue objects of empirical intuition really do fall under the Categories, and also

(ii) that there really are no such things as essentially rogue objects of empirical intuition,

then the A Deduction has a logical gap in it, and thereby is unsound.

\section{Closing the Gap 1: Take Three Steps}

In the $\mathrm{B}$ edition of the $C P R$, and correspondingly in the B Deduction, Kant takes three steps to close The Gap.

The first step is to define an essentially narrower conception of Erkenntnis that rules out empty concepts as 'cognitions' in the strict sense of that term, and also thereby guarantees, by stipulation, that all cognitions in the narrow sense are objectively valid empirical judgments, or judgments of experience (CPR Bxxvi n.).

The second step is to deploy a strong version of TI which entails the identity thesis that

$\square(\forall \mathrm{x})$ ( $\mathrm{x}$ is an experience of an object $=\mathrm{x}$ is an object of experience) or at the very least, entails the necessary equivalence thesis that

$\square(\forall x)$ ( $x$ is an experience of an object if and only if $x$ is an object of experience).

In other words, for Kant, all the experiences of objects, in the form of objectively valid judgments of experience, are either necessarily identical to or necessarily equivalent with all the objects of experience. This experience of objects/objects of experience necessary identity or necessary equivalence thesis is clearly implied by the crucial last sentence of the crucial section $\$ 26$, which says that 'since experience is cognition through connected perceptions, the categories are conditions of the possibility of experience [i.e., of all experiences of objects], and are thus valid a priori of all objects of experience' (CPR B161). But it also explicitly stated in Kant's philosophical correspondence:

You put the matter quite precisely when you say: 'The content (Innbegriff) of a representation is itself the object; and the activity of the mind whereby the content of a representation is represented is what is meant by "referring to the object"' (PC 11: 314). 


\section{Robert Hanna}

Now the first two steps, together with The Togetherness Thesis, directly entail

(i) that 'blind' intuitions are not cognitions (in the narrow sense of 'cognition') and also

(ii) that objects of 'blind' intuition are not really objects (of experience).

Notice that if the crucial qualifications in parenthesis are left out or overlooked, then it can easily seem that Kant is just a Conceptualist, full stop, and not in fact an essentialist content Non-Conceptualist who is also a deeply conflicted Conceptualist. But that is entirely the result of a superficial reading of the text, although of course grist for the hermeneutic mills of those who (falsely) believe that Kant is a Conceptualist, full stop, e.g.,

In his slogan, 'Thoughts without content are empty, intuitions without concepts are blind', Kant sums up the doctrine of conceptualism. ${ }^{17}$

But of course, as we have already seen, Kant himself is a deeply conflicted Conceptualist who is desperately trying to close The Gap in the Deduction that has been opened up by his own essentialist content Non-Conceptualism. So more than a definitional sleight-of-hand is needed to solve the problem.

The third step, therefore, is explicitly to construe the transcendental synthesis of the imagination, a.k.a. 'figurative synthesis', a.k.a. 'synthesis speciosa', a.k.a. 'the productive imagination', as the mere 'effect' of understanding on sensibility, presupposing the original synthetic unity of apperception, and therefore also presupposing the Categories:

Since in us a certain form of sensible intuition a priori is fundamental, which rests on the receptivity of the capacity for representation (sensibility), the understanding, as spontaneity, can determine the manifold of given representations in accord with the synthetic unity of apperception, and thus think a priori synthetic unity of the apperception of the manifold of sensible intuition, as the condition under which all objects of our (human) intuition must necessarily stand, through which then the categories, as mere forms of thought, acquire objective reality, i.e., application to objects that can be given to us in intuition, but only as appearances; for of these alone are we capable of intuition a priori. This synthesis of the manifold of sensible intuition, which is possible and necessary a priori, can be called figurative (synthesis speciosa) .... Yet the figurative synthesis, if it pertains merely to the original synthetic unity of apperception, i.e., this transcendental unity, which is thought 
in the categories, must be called .... the transcendental synthesis of the imagination. Imagination is the faculty for representing an object even without its presence in intuition. Now since all of our intuition is sensible, the imagination, on account of the subjective condition under which it alone can give a corresponding intuition to the concepts of understanding, belongs to sensibility; but insofar as its synthesis is still an exercise of spontaneity, which is determining and not, like sense, merely determinable, and can thus determine the form of sense a priori in accordance with the unity of apperception, the imagination is to this extent a faculty for determining the sensibility a priori, and its synthesis of intuitions, in accordance with the categories, must be the transcendental synthesis of the imagination, which is an effect of the understanding on sensibility and its first application (and at the same time the ground of all others) to objects of the intuition that is possible for us. As figurative, it is distinct from the intellectual synthesis without any imagination merely through the understanding. Now insofar as the imagination is spontaneity, I also occasionally call it the productive imagination (CPR B151-152).

The same line of argument was present in the A Deduction, but not nearly as clearly and explicitly. In any case, this long-winded text clearly and explicitly means that necessarily, for all objects of rational human cognition, for every object of empirical intuition to which the transcendental imagination possibly applies, i.e., for every object of empirical intuition that is able to be cognitively processed by means of the figurative synthesis or synthesis speciosa or productive synthesis of the imagination, i.e., for every object of empirical intuition that we can determinately and uniquely locate in the total space and time of material natural-scientific objects, via the original synthetic unity of apperception, then it does indeed fall under the Categories and is also an object of experience. This line of argument does not quite line up with Kant's thesis that 'since all our intuition is sensible, the imagination .... belongs to sensibility' (CPR B151), but no matter. It suffices to show that necessarily, all the accidentally rogue objects do indeed fall under the Categories.

\section{Essentially Rogue Objects and the Failure of the B Deduction}

Unfortunately, however, the three steps do not suffice to show that there are no such things as essentially rogue objects. Such objects would be objects 


\section{Robert Hanna}

of empirical intuition represented by ENCC that are somehow or another engaged in nomological deviance and Categorial anarchy. What kinds of nomologically deviant, Categorially anarchistic objects are we talking about here? In fact, in various places, Kant explicitly allows for at least five different kinds of essentially rogue objects:

(1) Incongruent counterparts like my own right and left hands are objects of outer sense/spatial intuition that cannot be uniquely individuated by empirical concepts and/or schematized pure concepts, or by judgments of experience (see $D S, P$, and $O T$ ).

(2) Arbitrarily-chosen sequences of successive states in inner sense or phenomenal consciousness, including sensory states, desires, and affects, i.e., the temporal stream of consciousness, are non-mathematizable objects in inner sense or phenomenal consciousness that cannot be uniquely individuated by empirical and/or schematized pure concepts, or by empirical apperceptions = judgments of experience of the form 'I think X' (see the second Analogy of Experience, so-called 'judgments of perception' in $P$, and the Introduction to MFNS).

(3) The empirical affinity of the laws of nature does not automatically follow from the transcendental affinity of the laws. This entails the possibility of essential rogueness, nomological deviance, and Categorial anarchy in a causal sense $=$ causal perversity or non-determinism via transcendental freedom (see the third section of the A Deduction, $\$ 13$ of the B Deduction, the Third Antinomy of Pure Reason, the Critique of Practical Reason, and the first Introduction to CPJ).

(4) Non-inert and non-mechanical, and dynamically vitalistic or spontaneous, events, processes, or objects, and all naturally purposive or self-organizing objects of empirical intuition, i.e., living organisms-including plants (e.g., blades of grass), animals, and my own living conscious feeling body and its non-selfconsciously conscious vital or intentional movements (see esp. CPJ 5: 278, where mind is explicitly identified with life)—cannot be uniquely individuated by empirical concepts and/or schematized pure concepts, or by judgments of experience, since these all presuppose that their objects are made of inert and mechanical matter.

(5) And finally the operations of the power of artistic genius and its Ideas of imagination, i.e., creative mind, by means of which 'nature gives the rule to art' and in turn 'gives the rule to nature' (CPJ 5: 308) cannot be uniquely individuated by empirical concepts and/or schematized pure concepts, or by judgments of experience.

Q: What do incongruent counterparts like my right and left hands, the stream of phenomenal consciousness, causal perversity or non-determinism via 
transcendental freedom, organismic life including minded animal bodily life, and creative mind all have in common? A: They are all individually necessary conditions of embodied practical freedom, a.k.a. embodied rational agency. All that needs to be added is rational human personhood, and then the $5+1=6$ necessary conditions are also jointly sufficient for embodied rational agency.

The bottom line, however, is that the B Deduction shows that the Categories are necessary a priori conditions of the possibility of all and only objects of experience. But, given the existence of ENCC and the fivefold possibility of essentially rogue objects of empirical intuition, then the B Deduction does not suffice to show that the Categories must apply to all objects of the senses or all objects of empirical intuition. Now as we saw above, that is the stated goal of the B Deduction in \$§23-24. So the B Deduction fails.

\section{Closing the Gap 2: The Regulative Use of Ideas of Pure Reason and the third Critique}

Kant at least implicitly recognizes that the Deduction is unsound, which is why he includes the appendix on the regulative use of the Ideas of pure reason in the first Critique (CPR A642-668/B670-696). Kant argues that we must scientifically investigate nature as if we could cognize it according to pure rational principles of the 'homogeneity, specification, and continuity of forms' (CPR A658/B686), i.e., the systematic unity of nature, which is a merely regulative or 'hypothetical' use of reason, by means of which this 'systematic unity (as a mere idea) is only a projected unity' (CPR A647/B675). Nevertheless, this projected systematic unity is itself a necessary presupposition of the coherent use of the understanding (CPR A651/B679), and 'without it no empirical concepts and hence no experience would be possible' (CPR A654/B682). So this is Kant's proposed solution to the empirical affinity problem.

Correspondingly, in the first Introduction to the Critique of the Power of Judgment, and in the Analytic of the Beautiful, the 'principle of purposiveness' which is a necessary presupposition of the experience of the beautiful is the essentially nonconceptual awareness of the apparent conformity of nature to our cognitive faculties: we experience the beautiful as if nature were designed to conform to our cognitive faculties. That is, the experience of the beautiful gives us positive subjective evidence that there are no objects that are inherently at odds with the natural mechanistic laws generated and recognized by our cognitive faculties.

Also in the third Critique, teleological judgments about natural purposes and living organisms are a necessary supplement to mechanistic physics, since

it is quite certain that we can never come to know the organized beings and their internal possibility in accordance 


\section{Robert Hanna}

with merely mechanical principles of nature, let alone explain them; and indeed this is so certain that we can boldly say that it would be absurd for humans even to make such an attempt or to hope that there may yet arise a Newton who could make comprehensible even the generation of a blade of grass according to natural laws that no intention has ordered; rather we must absolutely deny this insight to human beings. (CPJ 5: 400).

\section{The Gap That Will Not Close: The Super-Sensible Substrate and the Aether-Deduction}

But in the third Critique, it is also made perfectly explicit that even though it is subjectively necessary for us to judge nature with respect to its beauty and artistic creativity and organismic life/purposiveness in order to effect a systematic cognitive transition from Nature to Freedom and to postulate their unity in a single 'supersensible substrate', i.e., God, who can grasp the teleological unity of freedom and nature via an 'intuitive understanding' that 'goes from the synthetically universal (of the intuition of the whole as such) to the particular, i.e., from the whole to the parts' (CPJ 5: 406-407), nevertheless these are all at most regulative and not constitutive judgments. For example, hylozoism, or the thesis that living matter exists, e.g., is a strictly noumenal, inherently contradictory (since physical matter is essentially inert), and unknowable thesis (CPJ 5: 394-395).

Finally, in the unfinished Transition from the Metaphysical Foundations of Natural Science to Physics project contained in the Opus postumum, Kant argues in the socalled 'Aether Deduction' that an a priori material condition of the possibility of experience is an actual material correlate of the supersensible substrate, i.e., the dynamic aether, existing as the unified totality of attractive and repulsive forces, and as the dual causal source of inert matter (natural mechanisms) and also natural purposes (living organisms) alike (OP 21: 206-233). This is basically a modified Spinozistic move, because it in effect construes physical nature, i.e., the dynamic aether, existing as the unified totality of attractive and replusive forces, and as the dual causal source of inert matter (natural mechanisms) and also natural purposes (living organisms) alike, as God's externalization, hence as deus sive natura.

But even if the Aether Deduction were sound, and even if it were appended to the B Deduction, their conjunction is still not sufficient to capture the essentially rogue, nomologically deviant, and Categorially anarchistic objects of empirical intuition represented by ENCC—e.g., incongruent counterparts like my right and left hands, the stream of phenomenal consciousness, causal perversity or non-determinism via transcendental freedom, organismic life, or creative mind-and bring them safely under empirical concepts and/or 
schematized Categories, or judgments of experience. So The Gap remains essentially unclosed at the very limits of Kant's transcendental idealism, like Kierkegaard's abyss of 70,000 fathoms, providing at once a counsel of deep skeptical despair (The Gap That Will Not Close) and also a breathtaking new possibility for transcendental idealism-the possibility of affirming The Gap.

\section{Closing The Gap $=$ Hegelian Absolute Idealism + Super-Conceptualism}

In the face of The Gap, we can see that there is a sufficient philosophical reason for Hegel's rejection of the very idea of ENCC, and for a corresponding radicalization of Kant's Conceptualism, as worked out step-by-step by Hegel in Faith and Knowledge, ${ }^{18}$ in the Phenomenology of Spirit (especially in the section on 'Sense Certainty', which in effect construes NCC as the mythical causal-sensory 'given'), and above all in the Science of Logic. There, in the Introduction to The Theory of the Concept, 'On the Concept in General', Hegel explicitly spells out not only the basics of Kant's deeply conflicted Conceptualism, but also the basics of his own post-Kantian, post-Critical AI and super-Conceptualism. Here are the relevant texts.

It is one of the profoundest and truest insights to be found in the Critique of Pure Reason that the unity which constitutes the nature of the Concept is recognized as the original synthetic unity of apperception, as unity of the I think, or of self-consciousness. This proposition constitutes the so-called transcendental deduction of the categories; but this has always been regarded as one of the most difficult parts of the Kantian philosophy, doubtless for no other reason than that it demands that we should go beyond the mere representation of the relation in which the $I$ stands to the understanding, or concepts stand to a thing and its properties and accidents, and advance to the thought of that relation. An object, says Kant, is that in the concept of which the $\overline{\text { manifold }}$ of a given intuition is unified. But all unifying of representations demands a unity of consciousness in the synthesis of them. Consequently it is this unity of consciousness which alone constitutes the connection of the representations with the object and therewith their objective validity and on which rests even the possibility of the understanding.... [T] he principles of the objective determination of concepts are, he says, to be derived solely from the principles of the transcendental unity of apperception. Through the categories which are these objective 


\section{Robert Hanna}

determinations, the manifold of given representations is so determined as to be brought into the unity of consciousness. According to this exposition, the unity of the concept is that whereby something is not a mere mode of feeling, an intuition, or even a mere representation, but is an object, and this objective unity is the unity of the ego with itself. In point of fact, the comprehension of an object consists in nothing else than that the ego makes its own, pervades it and brings it into its own form, that is, into the universality that is immediately a determinateness, or a determinateness that is immediately universality. As intuited or even in ordinary conception, the object is still something external and alien. When it is comprehended, the being-in-and-for-itself which it possesses in intuition and pictorial thought is transformed into a positedness, the $I$ in thinking it pervades it. But it is only as it is thought that the object is truly in and for itself; in intuition or ordinary conception it is only an appearance. Thought sublates the immediacy with which the object at first confronts us and thus converts the object into a positedness but its positedness is its being-in-and-for-itself, or its objectivity. The object therefore has its objectivity in the Concept and this is the unity of self-consciousness into which it has been received; consequently its objectivity, or the Concept, is itself none other than the nature of self-consciousness, has no other moments or determinations than the $I$ itself (SL 584-585, underlining added).

The Kantian exposition cited above contains two other features which concern the Concept and necessitate some further observations. In the first place, the stage of the understanding is supposed to be preceded by the stages of feeling and intuition, and it is an essential proposition of the Kantian transcendental philosophy that that without intuitions concepts are empty and are valid solely as relations of the manifold given by intuition. Secondly, the concept has been declared to be the objective element of knowledge, and as such, the truth. But on the other hand, the Concept is taken as something merely subjective from which we cannot extract reality, by which is to be understood objectivity, since reality is contrasted with subjectivity; and, in general, the Concept and the logical element are declared to be something merely formal which, since its abstracts from the content, does not contain truth (SL 585586, underlining added). 
Now whatever may be the forms of the stages which precede the Concept, we come ... to the relation in which the Concept is thought to these forms. The conception of this relation, both in ordinary psychology and in the Kantian transcendental philosophy is that the empirical material, the manifold of intuition and representation, first exists on its own account, and then the understanding approaches it, brings unity into it and by abstraction raises it to the form of universality. The understanding is in this way an intrinsically empty form, which, on the one hand, obtains a reality through the said given content and, on the other hand, abstracts from that content, that is to say, lets it drop as something useless, but useless only for the Concept. In both these actions, the Concept is not the independent factor, not the essential and true element of the prior given material; on the contrary, it is the material that is regarded as the absolute reality, which cannot be extracted from the Concept. Now it must certainly be admitted that the Concept as such is not yet complete, but must rise to the Idea which alone is the unity of the Concept and reality; and this must be shown in the sequel to be the spontaneous outcome of the nature of the Concept itself. For the reality which the Concept gives itself must not be received by it as something external but must, in accordance with the requirement of science, be derived from the Concept itself. But the truth is that it is not the material given by intuition and representation that ought to be vindicated as the real in contrast to the Concept. People often say, 'It is only a concept', contrasting the concept not only with the Idea but with sensuous, spatial, and temporal, palpable reality as something more excellent than the Concept; and then the abstract is held to be of less account than the concrete because it lacks so much of this kind of material (SL 587, underlining added).

If the superficial conception of what the Concept is, leaves all the manifoldness outside the Concept and attributes to the latter only the form of abstract universality or the empty identity of reflection, we can at once appeal to the fact that quite apart from the view here propounded, the statement or definition of a concept expressly includes not only the genus, which itself is, properly speaking, more than a purely abstract universality, but also the specific determinateness. If one would but reflect attentively on the meaning of this fact, one would see that differentiation 


\section{Robert Hanna}

must be regarded as an equally essential moment of the Concept. Kant has introduced this consideration by the extremely important thought that there are synthetic judgments a priori. This original synthesis of apperception is one of the most profound thoughts for speculative development; it contains the beginning of a true apprehension of the nature of the Concept and is completely opposed to that empty identity or abstract universality which is not within itself a synthesis. The further development, however, does not fulfill the promise of the beginning. The very expression synthesis easily recalls the conception of an external unity and a mere combination of entities that are intrinsically separate. Then again the Kantian philosophy has not got beyond the psychological reflex of the Concept and has reverted once more to the assertion that the Concept is permanently conditioned by a manifold of intuition. It has declared intellectual cognition and experience to be a phenomenal content, not because the categories are themselves only finite but, on the grounds of a psychological idealism, because they are merely determinations originating in self-consciousness. It is in keeping with this standpoint, too, that the Concept without the manifold of intuition is again declared to be empty and devoid of content despite the fact that it is a synthesis a priori; as such, it surely does contain determinateness and difference within itself. Moroever, since the determinateness is that of the Concept and therefore absolute determinateness, individuality, the Concept is the ground and source of all finite determinateness and manifoldness (SL 588-589, underlining added).

It will always stand out as a marvel how the Kantian philosophy recognized the relation of thought to sensuous reality, beyond which it did not advance, as only a relative relation of mere appearance, and perfectly well recognized and enunciated a higher unity of both in the Idea in general and, for example, in the Idea of an intuitive understanding, and yet stopped short at this relative relation and the assertion that the Concept is and remains utterly separate from reality-thus asserting as truth what it declared to be finite cognition, and denouncing as unjustified extravagance and a figment of thought what it recognized as truth and of which it established the specific concept (SL 592, underlining added).

Here, very roughly, Hegelian absolute Spirit or Geist $=$ Kantian reason + apperception + understanding + judgment + transcendental imagination + intuition, 
all fused into a single, integrated cognitive capacity or power, and thought is identical to being.

We can also see here the crucial distinction, which Eckart Förster very insightfully highlights in his recent book The Twenty-Five Years of Philosophy, between 'intellectual intuition' and 'intuitive understanding, ${ }^{19}$ both of which are complementary aspects of the pure rational Idea of divine cognition. Intellectual intuition is thinking that creates its own objects. Intuitive understanding, by sharp contrast, is the immediate cognition of a complete whole as a systematic unity, that also advances to all its proper parts as integrally and essentially related to the whole. Now Kant and Hegel agree that we are incapable of intellectual intuition. But where Kant and Hegel radically differ is that Hegel holds that we are capable of intuitive understanding, i.e., the logically dialectical, inherently developmental and dynamic, synoptically holistic, rational self-conscious thinking that immediately grasps a conceptual world-essence, a.k.a. the Concept, a.k.a. the concrete universal.

\section{Affirming The Gap: Taking Essentially Rogue Objects Really Seriously}

The real possibility of essentially rogue objects that is yielded by ENCC, as Timothy Williamson has recently rediscovered, undermines the truth of any version of Conceptualism that is weaker than Hegel's AI+super-Conceptualism:

For objects, McDowell's claim that the conceptual is unbounded amounts to the claim that any object can be thought of. Likewise for the sort of thing that can be the case: the claim is, for example, that whenever an object has a property, it can be thought, of the object and the property, that the former has the latter.... McDowell's argument in any case seems to require the premise that everything (object, property, relation, state of affairs, ...) is thinkable. That premise is highly contentious. What reason have we to assume that reality does not contain elusive objects, incapable in principle of being individually thought of?.... Although elusive objects belong to the very same ontological category of objects as those we can single out, their possibility still undermines McDowell's claim that we cannot make "interesting sense" of the idea of something outside the conceptual realm .... We do not know whether there are actually elusive objects. What would motivate the claim that there are none, if not some form of idealism very far from McDowell's intentions? We should adopt no conception of philosophy that on methodological grounds excludes elusive objects. ${ }^{20}$ 


\section{Robert Hanna}

Moreover, there is a fundamental four-way connection between Kant's essentialist content Non-Conceptualism, his empirical realism, his correspondence theory of truth, and a liberally naturalistic version of his theory of freedom of the will that I call The Embodied Agency Theory. ${ }^{21}$ Indeed, if I am correct, then the only way back to Kant's empirical realism, correspondence theory of truth, and The Embodied Agency Theory is via ENCC and affirming The Gap, i.e., accepting the real possibility and indeed the actuality of essentially rogue objects and the unsoundness of The Transcendental Deduction of the Categories, i.e., taking essentially rogue objects really seriously. Otherwise put, if we affirm The Gap and the unsoundness of The Transcendental Deduction of the Categories, then what we are saying is just that there are more kinds of things in the manifestly real natural world than inert matter and natural mechanisms, that fundamentally physical facts are not all the manifestly real facts, and that the manifestly real natural world also contains incongruent counterparts, the stream of phenomenal consciousness, causal perversity or non-determinism via transcendental freedom, natural purposes or living organisms, creative mind, persons, and embodied rational agents, all of which or whom are directly cognized and directly cognizable by us via essentially non-conceptual content. In short, this is liberal naturalism with a Kantian NonConceptualist attitude.

\section{Mind The Gap: Either/Or in Two Senses}

Hegel brilliantly recognizes that all Kant's strategies for closing The Gap in the Deductions fail, and also that only $\mathrm{AI}+\mathrm{SC}$ will do the job. So if you are going to be a consistent, successful Conceptualist, then your only option is just to accept Hegelian AI+super-Conceptualism: the identity of thought and being, and the intuitive understanding. Otherwise, any weaker version of Conceptualism will be defeated by the existence of ENCC and the real possibility of essentially rogue objects. If what $\mathrm{I}$ argued in section $\mathbf{X}$ is correct, however, then the metaphysical space opened up by NCC and The Gap is precisely what makes Kant's empirical realism, truth-as-correspondence, and embodied rational agency possible in a TI-based framework. So there has to be The Gap in the Deduction: otherwise it's the end of the world as we know it from the specifically rational human standpoint. Or to put it bluntly: No Gap, then no Kantian 'metaphysics with a human face', and no rational animals that are inescapably 'human, all too human', i.e., no Us.

By a radical contrast, Hegel's identity of thought and being+intuitive understanding is the world as it is known from the divine standpoint, and in this way Hegelian AI+super-Conceptualism is a post-Kantian, post-Critical radical resuscitation of classical Rationalist noumenal metaphysics, especially Spinoza, and what early Wittgenstein aptly calls die Anschaunng der Welt sub specie 
aeterni (Tractatus, 6.45). In short, it is a noumenal metaphysics whose 'content is the exposition of God as he is in his eternal essence before the creation of nature and finite mind' (SL 50).

Now in a contemporary philosophical context, there is much to recommend idealism. Above all, idealism offers a non-dualist, non-physicalist, non-empiricist, normatively robust, libertarian conception of rational human animals, other minded animals, and the larger social and natural worlds in which they live, move, and have their being. Moreover, in my opinion, idealism is the only viable contemporary alternative to what we might call The Big Parade of Scientism, i.e., the lockstep march of neo-Quinean empiricism and anti-realism, reductive or scientific naturalism in general, naturalistic modal metaphysics in particular, consequentialist ethics, and Experimental Philosophy, a.k.a. X-Phi, that collectively constitute the conventional wisdom in the most important AngloAmerican and Australasian departments of philosophy. That way madness lies, however, since if scientism were true, then the formal and natural sciences themselves, as rational human enterprises, would not be possible. ${ }^{22}$ In short, scientism is cognitive suicide, although its cultural, institutional, and political success in the post-1950s academic world of the military-industrial complex and global corporate capitalism also cannot be denied. It is no accident, then, that 'idealism' is generally a very bad word in these philosophy departments. Indeed, and ironically, it was only by constantly avoiding truly facing up to the excitingly dangerous metaphysics and epistemology of Hegel's absolute idealism that the contemporary Pittsburgh school neo-Hegelianism of Sellars, McDowell, and Brandom ever came to be. ${ }^{23}$ Here, Hegel's excitingly dangerous divine standpoint is replaced by the American pragmatist's safely familiar ideal communitarian/social-institutional standpoint, and Hegel's excitingly dangerous intuitive understanding is replaced by more benign epistemic options, e.g., Sellars's 'fusing the images', McDowell's 'naturalized platonism', or Brandom's 'rationalistic pragmatic expressivist inferentialism'.

But if the argument I have developed in this paper is sound, then as I mentioned above, it provides us with the crucially important philosophical moral of the story:

If you are going to be a contemporary Idealist, then the basic options are either

(i) Kantian essentialist content Non-Conceptualism+TI+affirming The Gap

or

(ii) Hegelian AI+ super-Conceptualism. You cannot consistently have it both ways, and therefore you will need to make your choice.

Contemporary neo-Hegelian attempts to defend Conceptualism, such as those developed by McDowell and Brandom, without going all the way to AI and super-Conceptualism, are doomed, because Kantian essentialist content 


\section{Robert Hanna}

Non-Conceptualism + TI + affirming The Gap trumps any version of Conceptualism that is weaker than super-Conceptualism. So it's an Either/Or, in two senses:

(1) Either idealism Or scientism, and

(2) Either forward-to-Kantian-Non-Conceptualism Or forward-toHegelian-super-Conceptualism.

For my own part, I think that Kant's buman-faced transcendental idealist metaphysics and epistemology provide a significantly better overall philosophical explanation of all the relevant philosophical data and facts than Hegel's God-drunk absolute idealist metaphysics and epistemology, mainly because I do think that Kant's cognitive dualaspectism and his radical agnosticism about things-in-themselves or noumena are simply correct. Cognitively and epistemically, even despite being inherently rational and capable of a priori knowledge of necessary truths, we are also inherently 'human, all too human', and all our a priori knowledge is inherently restricted to necessary truths about the manifestly real natural world and the manifestly real human persons and other minded animals we directly encounter through sense perception and embodied phenomenal consciousness. Therefore I choose option (i), forward-to-Kantian-Non-Conceptualism. But even if I am wrong about this, nevertheless option (ii), forward-to-Hegelian-super-Conceptualism, is still infinitely better than The Big Parade of Scientism, which, at the end of the philosophical day, is cognitive suicide. So Kant and Hegel teach us that, ultimately, the fate of non-conceptual content and the fate of philosophy itself are one and the same.

\section{Robert Hanna \\ University of Colorado robert.hanna@colorado.edu}

\section{Notes}

\footnotetext{
${ }^{1}$ For convenience I refer to Kant's works and to Hegel's works internally, that is, infratextually in parentheses.
}

The Kant citations include both an abbreviation of the English title and the corresponding volume and page numbers in the standard "Akademie" edition of Kant's works: Kants gesammelte Schriften, edited by the Königlich Preussischen (now Deutschen) Akademie der Wissenschaften (Berlin: G. Reimer [now de Gruyter], 1902-). For references to the first Critique, I follow the common practice of giving page numbers from the A (1781) and B (1787) German editions only. Because the Akademie edition contains only the B edition of the first Critique, I have also consulted the following German composite edition: Kritik der reinen Vernunft, ed. W. Weischedel, Immanuel Kant 


\section{Kant, Hegel, and the Fate of Non-Conceptual Content}

Werkausgabe III (Frankfurt: Suhrkamp, 1968). For references to Kant's Reflexionen, i.e., entries in Kants handschriftlicher Nachlaß — which I abbreviate as ' $\mathrm{R}$ '- I give the entry number in addition to the Akademie volume and page numbers. The translations from the Reflexionenare my own

The Hegel citations include an abbreviation of the English title and the corresponding page number(s) in the English translation. I have also consulted the corresponding German texts in the standard edition of Hegel's works: Werke in zwanæig Bänden, ed. E. Moldenhauer and K.M. Michel (Frankfurt: Suhrkamp, 1969-71).

In both cases I generally follow the standard English translations of the German texts, but have occasionally modified them where appropriate. Here is a list of the abbreviations and English translations of the works cited.

\section{Kant}

CPJ Critique of the Power of Judgment. Trans. P. Guyer and E. Matthews. Cambridge: Cambridge University Press, 2000.

CPR Critique of Pure Reason. Trans. P. Guyer and A. Wood. Cambridge: Cambridge University Press, 1997.

DS "Concerning the Ultimate Ground of the Differentiation of Directions in Space," in Immanuel Kant: Theoretical Philosophy, 1755-1770. Trans. D. Walford and R. Meerbote. Cambridge: Cambridge University Press, 1992, 361-372.

MFNS Metaphysical Foundations of Natural Science. Trans. J. Ellington. Indianapolis, IN: BobbsMerrill, 1970.

OP Immanuel Kant: Opus postumum. Trans. E. Förster and M. Rosen. Cambridge: Cambridge University Press, 1993.

OT "What is Orientation in Thinking?," in Kant: Political Writings. Ed. H. Reiss. Trans. H.B. Nisbet. $2^{\text {nd }}$ ed. Cambridge: Cambridge University Press, 1991, 237-249.

P Prolegomena to Any Future Metaphysics. Trans. J. Ellington. Indianapolis: Hackett, 1977.

PC Immanuel Kant: Philosophical Correspondence, 1759-99. Trans. A. Zweig. Chicago: University of Chicago Press, 1967.

VL 'The Vienna Logic', in Immanuel Kant: Lectures on Logic, 249-377.

\section{Hegel}

FK Faith and Knowledge. Trans. W. Cerf and H.S. Harris. Albany, NY: SUNY Press, 1977.

PS Phenomenology of Spirit. Trans. A.V. Miller. Oxford: Oxford University Press, 1977.

SL Science of Logic. Trans. A.V. Miller. London: George Allen \& Unwin, 1969.

${ }^{2}$ See, e.g., J. Bermúdez and A. Cahen, 2010; Edward N. Zalta (ed.) URL = http:// plato.stanford.edu/archives/spr2010/entries/content-nonconceptual/; G. Evans, 1982, esp. chs. 4-6, and Y. Gunther, 2003. 


\section{Robert Hanna}

${ }^{3}$ See, e.g., R. Hanna, 2001.

${ }^{4}$ See, e.g., J. McDowell, 1994 and J. McDowell, 2009.

${ }^{5}$ See, e.g., R. Brandom, 1994 and R. Brandom, 2000.

${ }^{6}$ For more details and explicit justifications of these definitions, see R. Hanna, 2011b: 321-396 and R. Hanna Metaphysics with a Human Face: Lectures on Kant's Critique of Pure Reason.

${ }^{7}$ See, e.g., R. Hanna, "Transcendental Idealism, Phenomenology, and the Metaphysics of Intentionality," in K. Ameriks and N. Boyle (eds.), 2013.

${ }^{8}$ See, e.g., R. Hanna 2012.

${ }^{9}$ See, e.g., T. Bayne and M. Montague (eds.), 2011.

${ }^{10}$ See, e.g., W. Sellars, 'Empiricism and the Philosophy of Mind', in W. Sellars, 1963: 127-196.

${ }^{11}$ See, e.g., P. Guyer, 'Thought and Being: Hegel's Critique of Kant's Theoretical Philosophy', in F. Beiser (ed.), 1993: 171-210.

12 See R. Hanna, 'Beyond the Myth of the Myth', 326-327; and McDowell, 'Avoiding the Myth of the Given', in McDowell, 2009: 256-272.

${ }^{13}$ See, e.g., R. Stern, 2009, esp. the Introduction, and chs. 1 and 5.

${ }^{14}$ See, e.g., Förster, The Twenty-Five Years of Philosophy; and Stern, Hegelian Metaphysics.

${ }^{15}$ See R. Hanna, 'Kant's Non-Conceptualism, Rogue Objects, and the Gap in the B Deduction', 2011a: 397-413.

${ }^{16}$ See R. Hanna, 'Kant and Nonconceptual Content', 2005: 247-290.

${ }^{17}$ Y. Gunther, 'Introduction', in Gunther (ed.), Essays on Nonconceptual Content, 1-19, at p. 1.

18 See, e.g., E. Wilson, “'Absolute Identity” and Hegel's Treatment of Concepts and Intuitions', 102-107.

${ }^{19}$ See also E. Förster, The Twenty-Five Years of Philosophy, esp. ch. 11.

20 T. Williamson, The Philosophy of Philosophy 2007: 16-17.

${ }^{21}$ See R. Hanna, Kant, Science, and Human Nature, esp. chs. 1-2, 5, and 8; and R. Hanna and M. Maiese, Embodied Minds in Action, esp. chs. 3-5.

22 See Hanna, Kant, Science, and Human Nature, esp. the Introduction and chs. 5-8.

23 See, e.g., P. Redding, Analytic Philosophy and the Return of Hegelian Thought, 2007; and C. Maher, The Pittsburgh School of Philosophy: Sellars, McDowell, Brandom, 2012.

\section{Bibliography}

Bayne, T. and Montague, M. (eds.), (2011), Cognitive Phenomenology. Oxford: Oxford University Press.

Bermúdez, J. and Cahen, A. 'Nonconceptual Mental Content.' Stanford Encyclopedia of Philosophy (Spring 2010 Edition) Edward N. Zalta (ed.), http:// plato.stanford.edu/archives/spr2010/entries/content-nonconceptual/. Brandom, R. (1994), Making It Explicit. Cambridge: Harvard University Press. Brandom, R. (2000), Articulating Reasons: An Introduction to Inferentialism. Cambridge: Harvard University Press. 
Evans, G. (1982), Varieties of Reference. Oxford: Clarendon/Oxford University Press. Förster, E. (2012), The Twenty-Five Years of Philosophy, trans. B. Bowman. Cambridge: Cambridge University Press.

Gunther, Y. (ed.) (2003), Essays on Nonconceptual Content. Cambridge: MIT Press. Guyer, P. (1993), 'Thought and Being: Hegel's Critique of Kant's Theoretical Philosophy', in F. Beiser (ed.), The Cambridge Companion to Hegel. Cambridge: Cambridge University Press.

Hanna, R. (2001), Kant and the Foundations of Analytic Philosophy. Oxford: Oxford University Press.

Hanna, R. (2005), 'Kant and Nonconceptual Content.' European Journal of Philosophy 13: 247-290.

Hanna, R. (2006), Kant, Science, and Human Nature. Oxford: Oxford University Press. Hanna, R. (2011a), 'Kant's Non-Conceptualism, Rogue Objects, and the Gap in the B Deduction.' International Journal of Philosophical Studies 19: 397-413.

Hanna, R. (2011b), 'Beyond the Myth of the Myth: A Kantian Theory of NonConceptual Content.' International Journal of Philosophical Studies 19: 321-396.

Hanna, R. Metaphysics with a Human Face: Lectures on Kant's Critique of Pure Reason. Available online at: 〈http://www.colorado.edu/philosophy/lecture_hanna_ metaphysics_with_a_human_face_lectures_winter11.pdf $\rangle$.

Hanna, R., unpublished ms. Cognition, Content, and the A Priori. Fall 2012 version. Hanna, R. (2013), 'Transcendental Idealism, Phenomenology, and the Metaphysics of Intentionality, in K. Ameriks and N. Boyle (eds.), The Impact of Idealism: Philosophy and Science. Cambridge: Cambridge University Press.

Hanna, R. and Maiese, M. (2009), Embodied Minds in Action. Oxford: Oxford University Press.

Maher, C. (2012), The Pittsburgh School of Philosophy: Sellars, McDowell, Brandom. London: Routledge.

McDowell, J. (1994), Mind and World. Cambridge: Harvard University Press.

McDowell, J. (2009), Having the World in View. Cambridge, MA: Harvard University Press.

Redding, P. (2007), Analytic Philosophy and the Return of Hegelian Thought. Cambridge: Cambridge University Press.

Sellars, W. (1963), 'Empiricism and the Philosophy of Mind,' in W. Sellars, Science, Perception, and Reality. New York: Humanities Press.

Stern, R. (2009), Hegelian Metaphysics. Oxford: Oxford University Press. Williamson, T. (2007), The Philosophy of Philosophy. Oxford: Blackwell. Wilson, E. (2004), “'Absolute Identity” and Hegel's Treatment of Concepts and Intuitions in Glauben and Wissen.' Hegel Jahrbuch 2: 102-107. 